\title{
Gaming Technologies in Facilitating Communication in Pre-School Age
}

\author{
Anton Penchev Stoykov
}

\author{
Trakia University, Stara Zagora, Bulgaria \\ Corresponding author.E-mail: stoykov70@abv.bg
}

\begin{abstract}
This article deals with the inclusion of gaming technologies in the kindergarten educational process to facilitate communication at this very sensitive in terms of its development age. Proposed is a gaming technology model creating conditions for improving the child's social and communication skills with regards to the following parameters: quality; content; structure and functions.
\end{abstract}

Keywords: gaming technologies, communication, gaming technology model

\section{INTRODUCTION}

Nowadays, there is an increased interest in the problems related to communication, this interest being associated with the proven significance of communication for the development of the individual's personality, attitude and most important traits. Preschool age is a sensitive period for this development due to which encouraging and supporting communication between children at kindergarten is highly important.

Preschool age is extremely important for the development of the child's personality and mental health. It is called the age of games since at this age games are the leading activity. Communication is a very important component of the child's life and for the extent to which the child will master the communication techniques, hence, his/her success in the process of growing up will depend on it. The communication of a child at preschool age with peers and adults help him/her develop his/her own communication skills within the visual situations in which communication takes place [1].

According to A. Klimenko "the acquisition of the necessary social skills and interpersonal communication skills, which the child is able to acquire only in the process of intensive speech and "age appropriated" game activity" [2].

Preschool teachers have, in a variety of global studies, reported that many children have a poor speech and language development, and thus need support The need for different modes to support communication is extensive. Preschool plays a key role in the child development, and it includes both daycare and kindergarten [3].

Often parents complain that it is difficult for preschoolers to communicate. All children are different, and each child has different problems. For example, it is very difficult for shy children to make the first contact. They are afraid of ridicule, refusal, evaluation by peers.

In other children who seem to communicate quite easily and naturally, communication does not bring the desired satisfaction.

This happens because at preschool age, children are just beginning to master the subtleties of communication [4]. According to a number of authors (D. Gyurov, B. Angelov, I. Koleva, E. Rusinova, A. Bodalev, E. Smirnova, G. Andreeva, M. Lisina, Y. Kolominski, U. Bronfenbrenner, G. Mead, etc.) its high level of development at this age is a requirement for the child's successful adaptation in a particular social environment, determining the practical significance of its improvement from a very early age.

Many research studies draw the attention to the fact that development of the communication skills has a direct effect on the child's mental development in preschool age and an overall effect on the child's performance (N. Vitanova, Z. Boguslavska, N. Galiguzova, M. Lisina, E. Smirnova, D.Aram and N.Hall, R. Bakeman, A. Jates, M.Wingate, etc.)

At the present stage of social development there are a number of difficulties in the children's interpersonal communication. These difficulties are associated with a deficiency in the child's schooling, culture and moral criteria. Spending more time in front of the TV or the computer, children tend to communicate less with both adults and peers. Hence, this makes them less responsive to the others. In order to overcome these difficulties, more time should be dedicated on developing the interpersonal communication and its encouragement. For this reason, the problem related to organizing the child's communication process with both adults and peers is a priority. In this connection there is a necessity of exploring new possibilities for its development. Considering the age-specific characteristics of the children aged 5-7 yrs., the most suitable means for achieving this 
are the gaming environment and the gaming technologies in particular, whose potential is still inadequately studied. A number of research studies are dedicated to their elaboration and introduction into the teaching practice, i.e. the works of D. Dimitrov, G. Ivanova, P. Pidkasistiy, G. Selevko, M. Stronin, L. Legran.

However, two important aspects of them are still to be further elaborated: limited is the number of the gaming technologies designed for children at preschool age and to the extent they exist, they stand out with one-sidedness understood as having their focus only on some aspects of the child's development but not the child's personality as a whole.

All this allows to highlight the contradiction between the recognition of the importance of the development of communication with regards to the socio-personal development of the child and the underdevelopment of pedagogical game technologies as part of the methodological tools to support this development in accordance with state educational requirements.

This contradiction determines the main ideas referring to the concept of the proposed in this article model for encouraging and developing communication among children aged 5-7 years.

Within the teaching process in the modern pedagogical science, the term "pedagogical technology" has appeared in search of solutions for universalization and rationalization of the interaction process.

This term originated in the $60 \mathrm{~s}$ of the $20^{\text {th }} \mathrm{c}$. in the USA and UK under the influence of the computers development and the appearance of new computer technology. Over the years, however, the meaning of this term became broader and includes "the application of principles and the development of methods for optimization of the educational process through analysis of the factors increasing the educational efficiency [5].

Summarizing the definitions of different authors, D. Dimitrov points out several main characteristics of technology. It is a "specific, socially developed tool for concretization of the overall mechanisms of human activity" [6]. "To technology as an activity and a product, three functions are assigned: integrating, modelling and translating" [6]. According to the same author, apart from the activity model, in technology incorporated is also a particular algorithm (supporting invariant) and a programme for its development. D. Dimitrov deals also with the concept "technological approach to the gaming activity management at kindergarten". In his opinion, this is "an approach which is based on the disclosed specifics of the technological activities and the characteristics of its products [6].

In the group of the pedagogical technologies, a particular place is reserved for the game-based pedagogical technologies which enjoy an increased interest nowadays. They include a large group of methods and means for organization of the teaching process in the form of various pedagogical games. Y. Krasovski makes an attempt to track down the development periods of the gaming technologies during the $20^{\text {th }} \mathrm{c}$.

The first period the author refers to the beginning of the 70 s when the business game was starting to be more widely used as a training method, mainly as part of the university programmes.

The second period the author refers to the beginning of the 80 s when the gaming technologies were used mostly for training of specialists in the sector of economic science.

The third period covers the end of the 80s when the gaming technologies were included on a mass scale in all university student training programmes.

The fourth period the author refers to the end of the $20^{\text {th }}$ century when on a mass scale games were made a part of all spheres of education [7].

D. Dimitrov proposes a definition of the gaming technology as "a systemically built procedural and structural integrity of interconnected procedures for focused creation of the activities and pedagogical varieties of the game" [6]. He believes that the parameters of gaming technologies are pre-determined by three models: /the target, conceptual and organizational-functional model/, by the supporting invariant (structuring algorithm) and its unfolding programme.

The same author also draws the attention to the concept of "standard gaming technology" which, in his opinion, "is based on and aims at the activity or pedagogical form of a given type /kind /of game". It is focused on the answers of the questions "how" to develop the relevant variation of the game and "what for" and "how" it should be used [6].

S. Ivanov highlights that the game-based pedagogical technologies and techniques play a decisive role for implementation of the aims and tasks of the pedagogical interaction at all its levels. They ensure the adequate gaming satisfaction of the child's basic needs and interests, the child's activity and its pedagogical guiding by the kindergarten teacher [8].

Another author of interest who draws the attention to introducing the game-based pedagogical technology into the educational and schooling process at kindergarten in terms of formation and development of the children's independent gaming activity, is G. Ivanova. She presents her own understanding about the nature of the game-based pedagogical technologies, i.e. "scientifically justified and practically significant combination of interrelated, consistent and joint actions and operations of the teacher and the children, specified as particular procedures and intended for the formation and development of the children's independent gaming activity and promoting their gaming culture [9].

\section{METHODOLOGY}

Compared to games in general, the gaming technology possesses its specifics - an exactly formulated educational objective and the relevant pedagogical results which can 
be justified and isolated in a pure form and are characterized by having an educational and cognitive focus.

Since in literature still there is no unanimity with regards to the gaming technologies design methods and still there are differences with regards to the game structure, many of the gaming activity structural elements are the same for the different approaches. As a rule, the authors use their empirical experience to design a game or when they borrow its structural components from other authors.

M. Korotkova, summarizing the opinions of different authors points out the following principles which in her opinion should be observed upon the design and introduction of the gaming technologies in the practice, i.e. the development principle; the modelling principle; the principle of combining gaming and didactic objectives; activity principle and communication principle [10].

Based on this theoretical analysis for the nature of the gaming technologies, their types and design methods, a model for communication skills development is designed on the basis of the gaming technologies. Considering the nature of communication as a social process and of the game as a basic activity at preschool age, the elaborated gaming technologies are focused on development of two types of skills-social and personal skills, i.e. skills for establishing individual friendship relations but also skills for establishing friendship relations with groups of peers and developing solid social relationships with them.

This principle which is at the basic of the model, creates conditions the child to understand the importance of the group in the game ("My group") in terms of goal accomplishment, good possibilities for expression and affirmation.

In our opinion, children's participation in group games is highly significant for the development of their social skills, generating a favourable attitude towards others, sharing, agreeing, tolerance and more positive relationships. They help the child understand that "goal accomplishment is a product of the group process, joint work, that satisfaction with the joint efforts is better in comparison with the individual accomplishment" [11].

Among the most important communication skills are the conversational skills, i.e. the ability to understand the other person's needs and desires, and ability to express one's own needs and desires in front of the others" [11]. These include ability to share personal information, ask questions and express interest and approval. These are abilities which help the child communicate with another child or groups of children.

By the gaming technologies model, conditions are created for developing the social contacts and communication skills between the children in terms of the following parameters [12]: quality; content; structure and functions.

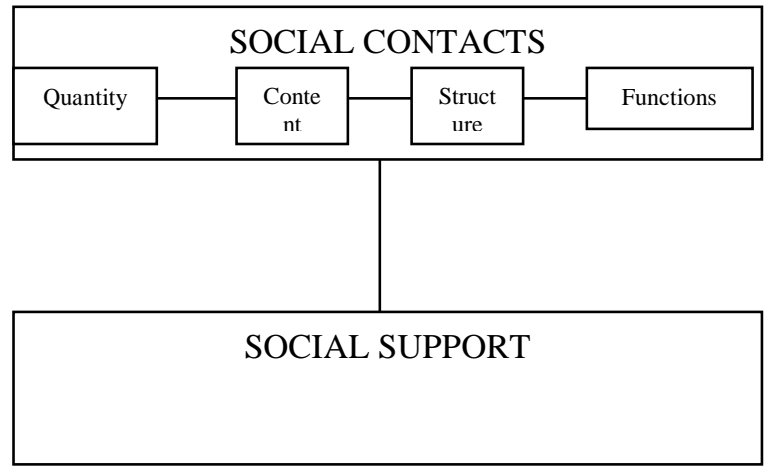

Figure 1 Model of Game Technologies for Increasing Social Contacts and Conversational Skills

By improving the child's social contacts (communication skills) and attachment which the child receives from the others while playing, the child starts to feel their social support. In our opinion, social support is important for the child's adaptation. Social support helps the child get to know the other people, himself/herself, to find a personal meaning of the interaction with others, to assert his/her individuality within the group while maintaining his/her autonomy and freedom of choice.

The proposed gaming technologies encourage communication among children within three systems: child-child; child-children and group-children. This process in presented in the figure below:

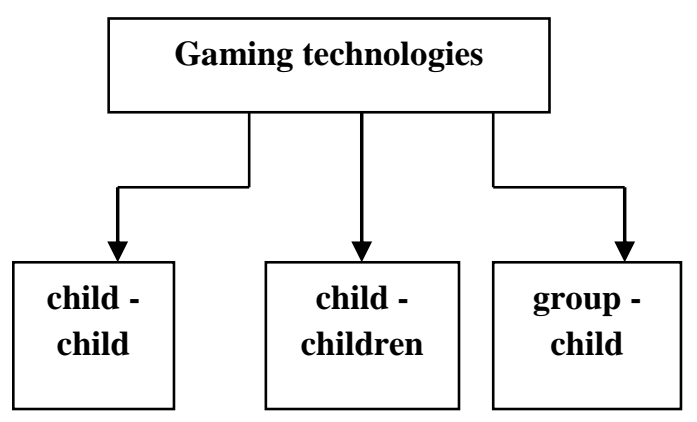

Figure 2 Encouraging Child's Communication by Gaming Technologies

For the successful outcome of the gaming technologies implementation process, pedagogical interaction is used which places in the center the child's personality. Such an interaction is personality-oriented. As a concept it has originated on the basis of the personality-centered education and is borrowed by the works of the renowned psychologist and teacher Carl Rogers, a representative of 
the humanistic approach in science. He makes a unique discovery, i.e. that the criteria for success in psychotherapy and teaching are the same.

The structure of the model includes two main game technologies: 1) technologies for the development of social communication skills; 2) technologies for the development of personal communication skills.

The first technology intended for developing social communication skills comprises the following game technologies: 1) ability for interaction and coherence of opinions, ideas and actions; 2) developing skills for evaluating the ideas, opinions, actions and behavior of others; 3) developing skills for cooperation / practical, cognitive, personal /;4) developing skills for making an empathic relationship.

The second game technology intended for developing personal communication skills comprises of game technologies for: 1) expressing the point of view for evaluation; 2) defending a position in the group; 3) more objective self-assessment and self-control, for expressing one's own opinion and for self-affirmation; 4) compliance with the group requirements, their understanding, observance and creation; 5) ability to read and interpret social signs; 6) identification, naming and expression of feelings; 7) reflexive skills; 8) skills for maintaining a positive self-image.

The technological process for the realization of the experimental model for the development of communication among children goes through two levels: the level of strategy of game technologies and the level of the specific game.

For the organization of learning to communicate, so that it contributes to the development of communication skills, it is necessary to take into account the potential capabilities of the child. Therefore, in the first place, the educational system should consider the child age-related needs together with the relevant social and ethical conditions. The child's needs should be satisfied by and embedded into the contents of education [4].

As a result, efforts are focused on creating and researching the effectiveness of the use of a model of game technologies with communicative focus in the organization of the pedagogical process in kindergarten on the acquisition of skills for a successful communication by children.

The Domino Game is used to measure the initiative of communication. The aim of the game is to encourage initiative in the communication among children and the formation of social skills to coordinate their actions.

Toolkit - one set of the Domino game is provided to every two teams of three children.

Instruction - the teacher instructs in advance all teams that in the course of the game the three participants from every team are obliged to give their consent before each new move of the game.

Procedure - the children are divided into teams of three participants. The dice determine the competing teams. The rules of the game are recalled. After all teams end their game, the children set up new teams on their own and the procedure is repeated.

The following criteria are taken into account when examining the intensity of communication:

Zero level - the child does not make contacts on his/her own initiative with his/her peers and does not make any efforts to attract their attention;

1. Low level - the child does not interact first, but shows initiative in response to the initiative of a peer or adult;

2. Intermediate level - the child shows initiative, but not always, acts insecurely, initiative appeals to peers or adults are not characterized by persistence;

3. High level - the child shows constant initiative of communication, demonstrates his/her abilities and tries to involve his peers in joint activities. Shows strong persistence in communication.

In connection with this, an experimental study was conducted, going through three stages - ascertaining, forming and control

During the formative stage of the experiment, the experimental model of game technologies for communication development was tested.

The study involved 162 children aged 5-7 years, of which 95 boys and 67 girls. The children were divided into control and experimental groups.

\section{RESULTS AND DISCUSSION}

The achieved results for the two studied groups regarding initiative in communication are the following:
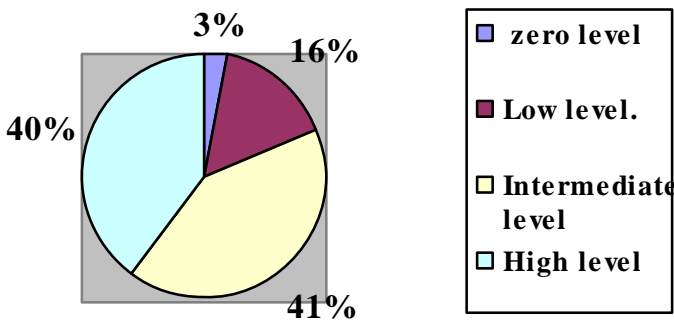

\section{Figure 3 Initiative in Communication}

The children from the two groups who achieved a high level in the criterion are $40 \%$. There is no significant difference between them - experimental group - 38\%, control group - 42\%. They showed interest in joint implementation of the assigned activity, demonstrated various ways to establish communicative contacts. In the course of the game activity they demonstrated a rich variety of communication techniques.

According to this criterion, $41 \%$ of the children from both groups achieved an average level of development. Most often they used uniform communication techniques (addresses) to attract the attention of their peers. 
A low level of development according to this criterion was observed in $16 \%$ of the children from both groups. Children who reached this level demonstrated a desire, willingness to communicate in response to the initiative, but they personally did not show such.

Zero level of development according to the criterion was observed in $3 \%$ of the children from both groups. They preferred independent games, did not seek contacts, cooperation or help from other children or adults.

The results of the experimental study are reflected in the following figure:

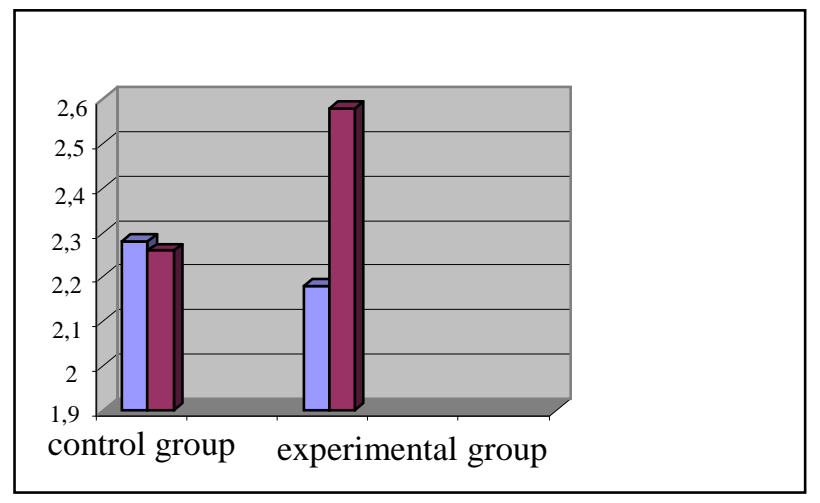

Figure 4 Initiative of Communication during the Ascertaining and Control Stages
The analysis of the results, made on the basis of their comparison, gives grounds to claim that in the children from the experimental group, in contrast to those from the control group, there is a more pronounced development of the initiative in communication after the formative stage of the experiment. Most of them showed themselves as initiators of communication in the course of the joint game activity and with greater success involved their peers in it. The number of ways to establish contacts is growing, which in our opinion can be explained with the acquired knowledge, including patterns for verbal and non-verbal communication.

The persistence demonstrated by the children from the experimental group in the process of communication was already more pronounced and it can be assumed that this is facilitated by some of the forms of pedagogical interaction included in the tested model ("Break the circle", "The new child" and etc.).

In children with a high level of initiative in communication from both groups, the indicators of intensity and extensiveness of free communication among them, also show high levels.

The obtained results are grounds to claim that the tested model of game technologies supports in a positive direction the initiative in the process of game communication.

Table 1 Results of the Analysis of Variance of Communication Initiative

\begin{tabular}{|c|c|c|}
\hline & $\mathbf{F}(\mathbf{1 , 1 5 0})$ & $\mathbf{p}$ \\
\hline$\{\mathbf{1 g r o u p}$ & 2.112 & 0.148 \\
\hline$\{\mathbf{2}\} \mathbf{s e x}$ & 1.274 & 0.261 \\
\hline \{3\}ethnicity & 3.468 & 0.065 \\
\hline group*sex & 0.455 & 0.501 \\
\hline group*ethnicity & 1.494 & 0.223 \\
\hline sex*ethnicity & 0.251 & 0.617 \\
\hline group*sex*ethnicity & 0.595 & 0.442 \\
\hline \{4\}test & 15.809 & 0.000 \\
\hline test *group & 4.361 & 0.038 \\
\hline test *sex & 0.111 & 0.740 \\
\hline test *ethnicity & 0.130 & 0.719 \\
\hline test *groyp*sex & 0.264 & 0.608 \\
\hline test *group*ethnicity & 0.972 & 0.326 \\
\hline test *sex*ethnicity & 0.133 & 0.716 \\
\hline
\end{tabular}

There is an anticipatory development of the intensity of contacts between girls compared to those between boys.
There is no significant increase in the intensity of contacts between children of different sexes. Marginally significant 
is the increase in the intensity of contacts between children from different ethnic groups, related to the closed lifestyle of children from the Roma ethnic group.

\section{CONCLUSION}

Based on the above theoretical analysis related to the nature, structure and functions of communication, its specifics at preschool age and the functional potential of the gaming technologies for its development, the following more important conclusions can be drawn:

1. Communication is a complex process for establishing and developing contacts between people, originating from their need of performing a joint activity and comprising exchange of information, elaboration of a single strategy for interaction, perception and understanding of the other person.

2. Communication turns out to be one of the most important needs of the individual and hence a requirement and a tool for its satisfaction. Without it, the most important personal needs related with the desire for selfrealization, self-expression and self-affirmation cannot be satisfied. In the process of communication itself, the individual develops and so do the individual's attitude and most important qualities.

3. Preschool age is a sensitive period for development of the child's communication skills. This development enables the child to adapt better in the social sphere, to establish numerous and complex relationships with the surrounding people and get involved into the moral norms of society.

4. Communication among children at preschool age is unfolded against the background of the practical and theoretical knowledge about the surrounding environment. 5. Gaming technologies as innovative pedagogical technologies create conditions for the better development of the child's cognitive, emotional and personal potential. 6. Gaming technologies create conditions for the establishment of spontaneous contacts, for a more active cooperation and encouragement of communication.

\section{REFERENCES}

[1] B. Zhonieva, Communications as the main factor of child development preschool age, International Journal on Integrated Education 2(III) 2019.

[2] A. Klimenko, Psychological features of interpersonal communication of senior preschoolers in the transition to school education, EUREKA: Social and Humanities 6 (2018) 19-24.

[3] J. Brodin, K. Renblad, Improvement of preschool children's speech and language skills, Early Child
Development and Care (2019). DOI: 10.1080/03004430.2018.1564917

[4] A. Hres, Rozvytok emotsiinoho intelektu. 5-6 rokiv, Osnova, 2018.

[5] International Yearbook of Education And Instructional Technology, 1978/1979, 1978.

[6] D. Dimitrov, Typical game technologies for kindergarten and primary school, 1989.

[7] G.K. Selevko, Modern educational technologies, National education, 1998.

[8] S. Ivanov, Pedagogical technologies of interaction in kindergarten, 2001.

[9] G. Ivanova, Pedagogical game technologies, 2000.

[10] M.V. Korotkova, Methods of holding games and discussions in history lessons, Vlados-Press, 2001.

[11] L. Shapiro, How to raise a child with a high emotional coefficient, Ugli, 1999.

[12] N. Vitanova, The activity of the child in kindergarten. A book for the teacher, Prosveta, 1993. 